\title{
Civismo e patriotismo na escolarização feminina no Brasil: a Escola de Economia Doméstica de Uberaba (Minas Gerais, 1953-1963)
}

\author{
Civic spirit and patriotism in female schooling in Brazil: the Home Economics School of \\ Uberaba (Minas Gerais, 1953-1963)
}

Civismo y patriotismo en la escolarización femenina en Brasil: La Escuela de Economía Domestica de Uberaba (Minas Gerais, 1953-1963)

\section{Ana Carolina Riccioppo ${ }^{1}$; Giseli Cristina do Vale Gatti ${ }^{2}$}

\section{Resumo}

Este texto objetiva demonstrar a importância da Escola de Economia Doméstica no processo de escolarização feminina levado a termo na cidade de Uberaba (Minas Gerais, Brasil), no período compreendido entre 1953 e 1963. Para tanto, partiu-se das ideias de Ratto (1992), Ferreira (2012 e 2014) e Ferreira \& Gonçalves Neto (2013). Em seguida, foi consultada a bibliografia de referência e examinada a documentação relacionada à legislação de ensino e a vida escolar em acervos públicos e da própria instituição. Verificou-se um processo de escolarização do cotidiano doméstico, no qual se coadunaram civismo, patriotismo e preceitos morais católicos, em uma instituição escolar que recebia jovens de Uberaba e de cidades próximas, para que elas aprendessem a desempenhar o papel de gestoras da família, baseadas na aquisição de conhecimentos científicos e de valores católicos, cujo destino seria o matrimônio e o lar, mas, também, no caso daquelas que pudessem precisar, a produção agrícola relacionada à subsistência familiar.

Palavras-chave: História, Educação Feminina, Escola, Economia Doméstica, Uberaba, Minas Gerais.

\footnotetext{
${ }^{1}$ Mestre em Educação pela Universidade de Uberaba. E-mail: carolriccioppo@uol.com.br

${ }^{2}$ Doutora em Educação, com estágio de pós-doutorado concluído no Programa de Pós-Graduação em Educação da Universidade Federal de Uberlândia. Professora do Programa de Pós-Graduação em Educação da Universidade de Uberaba. Beneficiária do Edital Universal da Fapemig e do CNPq. E-mail:giseli.vale.gatti@gmail.com
} 


\begin{abstract}
The aim of this text is to show the importance of the Home Economics School (Escola de Economia Doméstica) in the process of female schooling developed in the city of Uberaba (Minas Gerais, Brazil) in the period from 1953 to 1963. The ideas of Ratto (1992), Ferreira (2012 and 2014), and Ferreira \& Gonçalves Neto (2013) served as a theoretical basis for this discussion. The reference bibliography was consulted and documentation examined in public archives and archives of the school itself in relation to teaching legislation and school life. This investigation revealed a process of schooling for domestic daily life, which combined civic spirit, patriotism, and Catholic moral precepts in a school institution that received youth from Uberaba and neighboring cities. Young women were to learn to perform the role of family managers based on acquisition of scientific knowledge and Catholic values, and their destination would be marriage and the home. Yet, in the case of those who might need it, there was also training in agricultural production related to family subsistence.
\end{abstract}

Keywords: History, Female education, School, Home economics, Uberaba, Minas Gerais.

\title{
Resumen
}

Este texto tiene como objetivo demostrar la importancia de la Escuela de Economía Domestica en el proceso de escolarización femenina llevado a cabo en la ciudad de Uberaba (Minas Gerais, Brasil), en el periodo comprendido entre 1953 y 1963. Para ello, se parte de las ideas de Ratto (1992), Ferreira (2012 y 2014) y Ferreira \& Gonçalves Neto (2013). Posteriormente, fue consultada la bibliografía de referencia y examinada la documentación relacionada a la legislación de la enseñanza y la vida escolar en acervos públicos y de la propia institución. Se verificó un proceso de escolarización de lo cotidiano doméstico, en el que se reunieron civismo, patriotismo y preceptos morales católicos en una institución escolar que recibía jóvenes de Uberaba y de ciudades próximas, para que ellas, aprendieran a desempeñar el papel como gestoras de la familia, basándose en la adquisición de conocimientos científicos y de valores católicos, cuyo destino seria el matrimonio y el hogar, pero, también, en el caso de aquellas que lo pudieran necesitar, la producción agrícola relacionada con la subsistencia familiar.

Palabras-clave: Historia; Educación Femenina; Escuela; Economía Domestica; Uberaba; Minas Gerais. 


\section{Introdução}

No Brasil, mas, também, em outros países pelo mundo, o ideal de formação cívicopatriótica tão caro à concepção clássica de Modernidade, no qual o bem público estaria acima dos interesses particulares, levando a formação do bom cidadão, coadunava-se ao esforço de preservação da relevância da Igreja Católica, para o que concorriam diversas ações, entre as quais, o papel que teria a mulher no âmbito da vida familiar e da comunidade citadina, colaborando para a formação do bom cristão, neste caso, católico.

A partir destas prerrogativas gerais, pôde-se conhecer o contexto histórico mais geral que tornou possível o empreendimento da criação, em 1953, da Escola de Economia Doméstica na cidade de Uberaba, em Minas Gerais, para o que concorreram ações de lideranças católicas e da sociedade local. O funcionamento efetivo do curso ocorreu logo no ano seguinte, em 1954, quando tornou-se real o esforço de escolarização das atividades domésticas, por meio de um processo de cientificação, a partir de uma estrutura escolar que foi se moldando e aperfeiçoando ao longo do tempo.

Nessa direção, a investigação realizada buscou evidenciar a relação existente entre a educação da mulher na Escola de Economia Doméstica e a busca de atendimento de duas dimensões simultaneamente, de um lado, a formação cívica e patriótica, vinculada aos processos de modernização da vida em sociedade, de cientificação e de inovação no mundo do trabalho, de outro lado, a preservação de valores católicos fundamentais no seio da família brasileira. Investigação circunscrita aos primeiros dez anos de funcionamento da Escola, entre 1953 e 1963, na qual foi necessário acessar a bibliografia de referência pertinente e a documentação impressa e manuscrita, em especial, a legislação de ensino e os documentos escolares, em acervos públicos e da própria Escola.

A exposição dos resultados da investigação está dividida em duas seções, na primeira, aborda-se o processo de criação, as finalidades em relação a educação feminina e o funcionamento inicial da Escola de Economia Doméstica em Uberaba; na segunda, abordamse os saberes disciplinares que se intencionava disseminar por meio do referido curso. Finalizase, com a elaboração de algumas considerações acerca da importância da Escola de Economia Doméstica no processo de escolarização feminina levado a termo em Uberaba.

\section{A criação, as finalidades e o funcionamento inicial da Escola de Economia Doméstica}

A formação feminina em economia doméstica na cidade de Uberaba foi iniciada mediante empenho de lideranças católicas, em especial do Padre Agostinho Zago, em consonância com interesses da sociedade civil, local e nacional. O curso de Economia Doméstica foi criado no interior do "Centro de Treinamento e Escola Rural de Magistério de Economia Doméstica" que receberia outras designações ao longo do tempo. Já em 1954, passou a ser nomeado "Escola de Magistério de Economia Rural Doméstica Dr. Licurgo Leite", em homenagem a um deputado federal de Minas Gerais que esteve envolvido no processo de criação da Escola, nomenclatura que perdurou até 1964, tendo recebido outras designações ao longo do tempo, até a atual, em vigor desde 2008, Instituto Federal de Educação, Ciência e Tecnologia do Triângulo Mineiro. ${ }^{3}$

\footnotetext{
${ }^{3}$ Ao longo de tempo a instituição que abrigava o curso de Economia Doméstica em Uberaba (Minas Gerais, Brasil), recebeu as seguintes designações: Centro de Treinamento e Escola Rural de Magistério de Economia Doméstica (1953); Escola de Magistério de Economia Rural Doméstica Dr. Licurgo Leite (1954); Colégio de
} 
Segundo Ferreira (2014, p. 204), a ação do Padre Agostinho Zago esteve ancorada em uma articulação da qual faziam parte o Estado, em especial o Ministério da Agricultura, a Igreja e a elite uberabense, que visava o estabelecimento de uma educação adequada para as mulheres, que estivesse em consonância com a disseminação da ideia de civilização, cívica e patriótica, todavia, sob viés católico, em um mundo que se modernizava.

Figura 1 - Notícia sobre a instalação da escola no jornal Lavoura e Comércio (8 ago.1953, p.1)

\section{Será solenemente instalada amanhā a Escola de Economia Domestica}

Presidirá á cerimonia o ministro da Agricultu ra - Magnificamente instalado o estabelecimento em predio doado pelo padre Agostinho Zago - Esperado hoje, nesta cidade, o sr. João 4hes: Cleofas

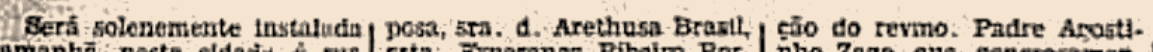
amanhä, nesta cldade, it run Mujor Eustaguio, B8, a Eornin de. Leonomia Domestiets.

A imponto cerimunia, programada para es la burtul, assiniala relevante congule-
tia pars esta comuni e tots a reusab, conslderando os apreclavels serylços que a estabeJeflmento prestari: a voeraba c to Trianigulo Mineiro.

A tinaudade da instiltulçio. de que um boa hora fol enri. quecido o patrimonio edueaclonial e cultural de nossa ter-

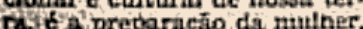
Ca, e a preparacalo da miner, notadamente a da zona r ural. pura cos trabulhos caselros. eseriliantara a colenjidide incurural 0 mintstro Joảo Cecotos, que, que aqul devera chesar hoje, as 10 horas, acompanhado de lusida cararana:

O. BIGANIFICADO DA INII CLATVA

A'trente do mortmento, de vo se espera rartu messe dn benefilolos para todo o Brasil Copitral, estāo, entre outros cestaendos batalmadares, o sr. of. Ewold Brasil, que no hado So rermo, padre Agostinho for fol Q grande reallzador

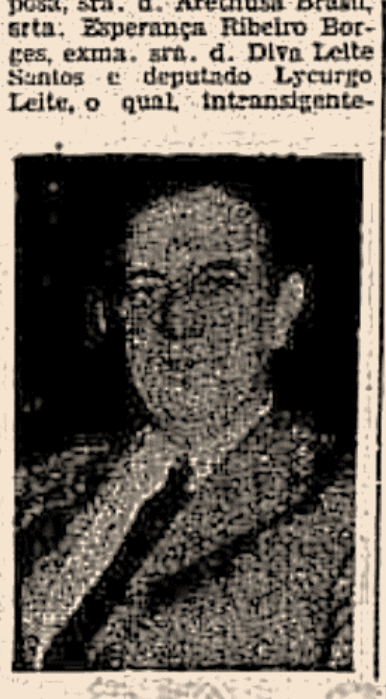

Minlatro Jaso Cleofis mente, se bateu peli obtinçito de vultosa terbs federnl, parz auxillo ao estabelecimento. Merece refarencis especial, e nío podemos delxar de fazo is, em prelto de Justiça, a A-

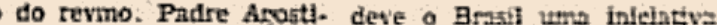
nho Zago, que, gencrosamen- / das mais reievants os prepa. te, doou a Instituiçâo, por in. rach̄o de nies de fnumilin pa. termedio do anisterio da A. ra tas 4 sus robre missio o ericultura, excelcnto prodlo Tecentemente construle recentemente constraied $\mathrm{E}$ run Major Eustaquito. Assim, a nava Eacola neara multo bem Instaliels num dos meIluores pontos da cidade. E juto pllieator, tambem, ac se possar err revista a atividade duzenvolvids para do. tar Liberaba de tăo spreciavel conqulsta, o traballo da exma. sra. d. Morta Jose Peside STa ciel (d. Sinhả), Laealizadora das escolas de economila, en toda o pals, e diretora do cs tabelecimento fundado no Río de Janelro.

Ao Idealimo, allado a nots. vol senso da realidade, que carncteriea a perionalladade de escol dessa insestre educadorn, mais cabal desoraponko. Merece aplausos, e tasnbern a reronbecimento fe todos o: ubsrabensess, a arajo do minte tro Jota Cleolas, que mostros sempre, em tedins as fases do empreendinertio, atom viforioso a major a mais animm. rosa, a ma dora bou voniado, tup fazen. co, no que estava na gat alya. da, para remover as dillecuto dades que te apresentavam aos promotores do movimento PBOFUNDO INTERESSE DESPERTADO PELA IS. COLA DE ECONOMIA

Asdralase, nesta e em rathes outras reglass do pais. profundo interese derpertoio pela Ercola de Economia Do (Segue at $6=2$ pag:?

Fonte: Lavoura e Comércio, 8 ago. 1953, p.1

Disponível em http://memoria.bn.br/pdf/830461/per830461_1953_13259.pdf. Acesso em 10 jun. 2018.

Estava claro que as escolas eram tomadas como um meio capaz de aprimorar a vida das famílias, as condições de vida doméstica e da sociedade, no sentido que ansiava o poder oligárquico regional e nacional, ou seja, em uma perspectiva de manutenção e conservação da ordem vigente, ainda que em um contexto de constante modernização e ajustamento social. Transparece no discurso de personalidades da cidade a representação do caráter positivo e progressista da instalação de novas escolas em Uberaba, conforme se pode examinar em Mendonça (1954, p.1):

Economia Doméstica Rural Dr. Licurgo Leite (1964); Escola Agrotécnica Federal de Uberaba Dr. Licurgo Leite (1979); Instituto Federal de Educação, Ciência e Tecnologia do Triângulo Mineiro, Uberaba (desde 2008). 
A Escola de Economia Doméstica, que se abre em Uberaba, foi a segunda que no Brasil se instala. [...]. O povo uberabense, que nestes rincões centrais do país, pelo seu bendito idealismo e pela sua incomparável capacidade de esforço e de trabalho, criou uma civilização de que todo o Brasil se ufana [...] (Mendonça, 1954, p.1).

No que se refere as finalidades educacionais, a Escola tinha objetivos precisos, relacionados à formação da gestora do lar, na direção de conferir eficiência à condução dos trabalhos da organização da casa e nos cuidados com a saúde familiar, que deveriam estar sob a responsabilidade de uma esposa bem preparada para essa missão. Para Ferreira \& Gonçalves Neto (2013, p.256),

O Curso de Economia Doméstica concebia uma formação para as moças adequada à direção de sua casa, para o cuidado com os filhos e para atender às questões de higiene básicas. Propiciava também uma formação condizente com a nova ordem urbana industrial em ampla expansão no Brasil, a partir de 1950, o que levava as donas de casa a valorizar tudo o que pudesse contribuir para uma administração eficiente do lar e que pudesse suavizar a dura rotina dos serviços domésticos diários.

É importante mencionar que o curso de Economia Doméstica começou a ser ofertado em um período histórico, a década de 1950, no qual poucas mulheres frequentavam o ensino secundário no Brasil, o que não era diferente na cidade de Uberaba, sobretudo, porque, a mulher era vista com atuação na vida doméstica, sendo exaltada como possuidora de um perfil moderado, protetor da moral e dos bons costumes. Nessa direção, o curso de Economia Doméstica poderia oportunizar para as mulheres o desenvolvimento da capacidade de planejamento do emprego de recursos naturais para suprir as necessidades da família no lar, por meio da aquisição de conhecimentos técnicos e de habilidades em relação aos múltiplos afazeres domésticos, que remontassem aos avanços e descobertas científicas.

Noutra perspectiva, no período compreendido mais diretamente neste artigo, de 1953 a 1963, é perceptível a valorização da mulher como representante da moral e dos bons costumes, conforme se pode depreender da leitura de um importante jornal católico de Uberaba na época, onde se lê:

Seja assim mais rico, mais perfeito e mais puro, o patrimônio moral e material que havemos de transmitir à geração que se segue. Graças a Deus que nesta hora como noutras lutas pela grandeza de nosso povo, a mulher brasileira está sabendo mostrar sua fibra, sua compreensão e sua nobreza de alma (Correio Católico, 29 ago. 1953, p. 5).

Segundo depoimento de uma ex-aluna que consta em Ferreira (2014, p. 328), a abordagem do Padre Agostinho Zago em busca de alunas que pudessem se matricular na escola era muito direta e ocorria do seguinte modo:

Eu me lembro, era maio. Estávamos conversando aqui em casa a respeito de festas. Era mocinha ainda. O Padre Zago chegou. Era muito amigo de meu pai. Éramos de Veríssimo[...]. Ele falou "Pílades, eu preciso conversar muito sério a respeito dessa menina aí". Eu fiquei muito assustada: "O que ele iria dizer?". "Eu vim aqui e você vai ceder sua filha como uma das candidatas para o Curso de Extensão Rural". 
Um amigo de meu pai, um paraguaio, estava hospedado aqui em casa e perguntou "O que essa menina entende de extensão rural, de economia doméstica, dessas coisas?". E o padre "Justamente, vai aprender [...]". O Padre Zago foi de porta em porta dos amigos dele e conseguiu formar uma turma bem grande (Ferreira, 2014, p.328).

No que se refere à proveniência das alunas, Ferreira (2014) afirma que elas eram da própria cidade de Uberaba, mas, também, de cidades relativamente próximas, tais como, Araxá, Frutal, Campo Florido, Conquista, Veríssimo, Araguari, Sacramento, Pirajuba, Prata e Conceição das Alagoas, sendo que a Escola "recrutou suas alunas em uma elite privilegiada: filhas de fazendeiros, advogados, comerciantes, bancários, industriais, funcionários públicos, policiais militares, ferroviários, médicos, entre outros, como registrado nos livros de matrículas" (Ferreira, 2014, p.287).

Na figura a seguir é possível visualizar a lista de alunas matriculadas em 1954, em um total de vinte e duas, com nome completo e data de nascimento. O número de alunas foi considerado bom, sobretudo, tendo em vista a forma como as moças tinham sido recrutadas pelo Padre Agostinho Zago, de porta em porta, por meio do convencimento dos pais a matricular suas filhas em um curso de Economia Doméstica.

Figura 2 - Relação de alunas matriculadas em 1954.

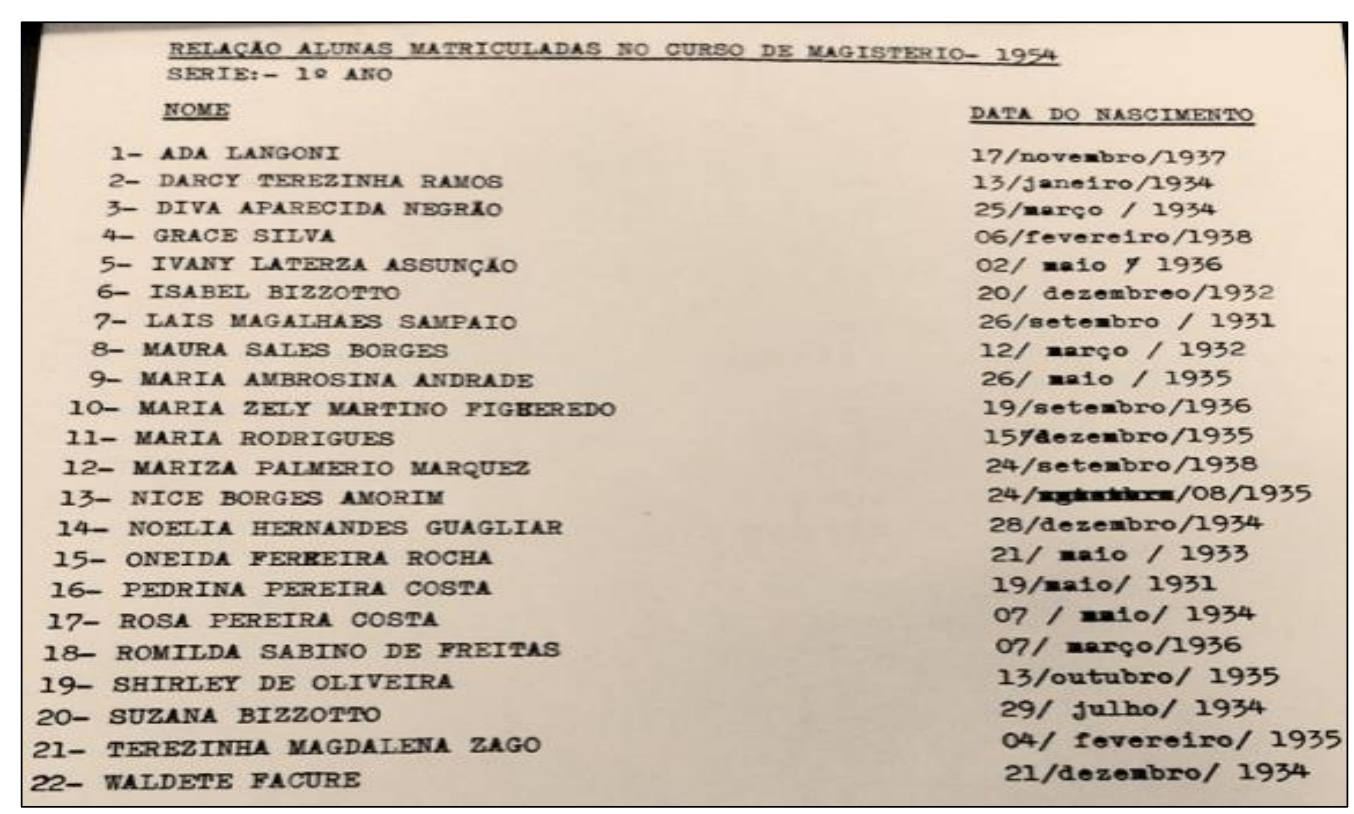

Fonte: Acervo do IFTM (Campus Uberaba).

No que se refere ao histórico de funcionamento da Escola de Economia Doméstica, o relato de Nice Borges Amorim é muito interessante e abrangente, pois, ela esteve vinculada à escola por mais de três décadas. Além de ter sido aluna, entre as décadas de 1950 e 1960, ela também trabalhou na escola e a dirigiu, em dois mandatos consecutivos (de 1982 a 1992) ${ }^{4}$. Em

\footnotetext{
${ }^{4}$ Em 2010, Nice Borges Amorim foi condecorada pelo Ministério da Educação brasileiro com a Medalha Nilo Peçanha, pela atuação que teve no desenvolvimento da educação técnica e profissional no Século XX. Nilo Peçanha foi presidente do Brasil entre 1909 e 1910, sendo que em seu curto mandato ele criou dezenove escolas de aprendizes e artífices, que originaram a educação profissional no Brasil. Para mais informações sobre o assunto, consulte o seguinte endereço na Internet: http://portal.mec.gov.br/component/tags/tag/34920-medalha-nilopecanha. Acesso em 10 jun. 2018.
} 
uma entrevista ao JM On Line, datada de 10 de fevereiro de 2012, ela fez um importante relato sobre sua vida na escola, sendo que reproduziremos, abaixo, alguns estratos deste texto, pois, apesar de se tratar de um texto autobiográfico, ele indica momentos importantes da Escola de Economia Doméstica:

Foi a abertura da minha vida profissional. Entrei no curso que chamava Magistério de Economia Rural e Doméstica e durava dois anos. Nessa época, a escola pertencia ao Ministério da Agricultura, e depois da reforma administrativa é que passou a estar ligada ao Ministério da Educação. Todo ensino agrícola era assim. [...]. Em 1956, a dona Aspásia Cunha Campos ia assumir a direção da escola, depois que a dona Laura Pinheiro ganhou uma bolsa para estudar nos Estados Unidos, e me perguntou se eu queria trabalhar na escola. Eu amava a escola e aceitei [...]. Começamos com cinco funcionárias que faziam tudo na escola, por isso, quando fui diretora, não tive dificuldade alguma, pois sabia fazer de tudo na escola. Tínhamos uma grande vontade de fazer a escola crescer, mesmo passando por situações sérias, com risco até de fechar. Primeiro, por falta de local para funcionar: antes era na Major Eustáquio, em um sobrado do padre Agostinho Zago. E justiça se faça, se existe o IFTM hoje, nós devemos ao padre Agostinho, porque na época ele tomava conta do abrigo de menores e tinha muito entrosamento com o Ministério da Agricultura, por onde mandava rapazes, hoje bem-sucedidos, para estudar fora. Ele mandou três uberabenses para estudar Economia Doméstica no Rio para abrir o curso aqui, através da Seagri (Secretaria de Ensino Agrícola Veterinário). [...] Mas, como a escola era um bem público, mudamos para um local alugado ao lado do Cine Metrópole, mas não tinha campo para as atividades agrícolas. Fizemos uma horta em um terreno ao lado [...] (Amorim, 2012).

Segundo o relato de Nice Borges Amorim, os vencimentos eram pagos anualmente, em setembro ou outubro. Todavia, houve dificuldades financeiras para manutenção do pagamento do aluguel do espaço em que funcionava à escola, o que levou à direção da escola a buscar o apoio do Ministério da Agricultura que primeiramente cedeu

um terreno no fundo da atual ABCZ, antiga Sociedade Rural do Triângulo Mineiro. Nossas alunas às vezes tinham aulas nos pavilhões do gado. Trabalhamos e conseguimos adquirir um terreno para construirmos algo para a escola, e tivemos a área e verba para construir quatro salas, onde funcionou o Cefet, ao lado da ABCZ. Com a implantação dos cursos voltados à agropecuária, em 1982, antes da escola-fazenda, os alunos traziam suas enxadas de casa e ensinávamos horticultura e avicultura no quintal desse espaço com a dedicação de professores como Djalma Bessa e de fazendeiros da região, que permitiam que os alunos fizessem visitas técnicas às fazendas (Amorim, 2012). 
Figura 3 - Primeiro prédio onde funcionou o curso de Economia Doméstica.

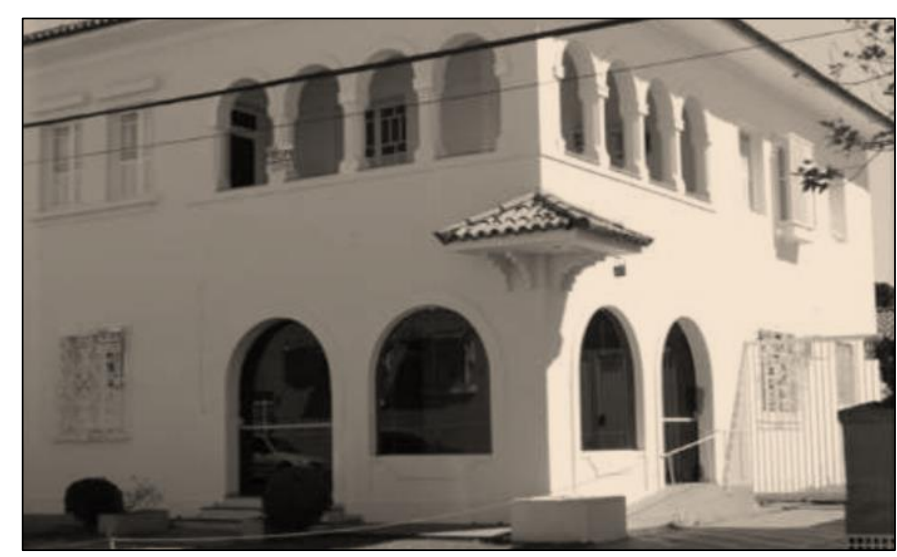

Fonte: Ferreira (2012, p.156)

Mais à frente, a escola deixou de ser subordinada ao Ministério da Agricultura e passou a ser subordinada ao Ministério da Educação, mais especificamente à Coordenação Nacional de Ensino Agropecuário (Coagre), quando passaria, em 1979, a ser denominada Escola Agrotécnica Federal de Uberaba Dr. Licurgo Leite. Houve, todavia, problemas, conforme relatou Nice Borges Amorim:

Fui a Brasília e fiquei sabendo que a escola não receberia recursos se não construíssemos uma escola-fazenda e, ainda, corríamos o risco de perder a Economia Doméstica, pois outras cidades estavam se oferecendo na Coagre. Cheguei aqui desorientada. O dr. Silvério Cartafina era prefeito na época e o padre Eddie Bernardes, coordenador educacional. Pedi ajuda e conseguimos a doação de 472 hectares para fazer a escola-fazenda. [...] Tivemos que convencer os vereadores, que chamavam de "negociata". Lá, construímos a escola-fazenda do zero, porque não existia absolutamente nada, a não ser uma cocheira velha, caindo aos pedaços. Fizemos parcerias técnicas com a Epamig, Emater, dr. Paulo Mesquita, Fosfertil, Sindicato Rural, Copervale, ABCZ, entre outras, e assim fomos conseguindo a estrutura necessária. Depois, o Wagner do Nascimento se encantou pela escola e deu nosso primeiro poço artesiano. E assim fomos conseguindo crescer (Amorim, 2012).

Percebe-se, desse modo, que, mesmo com apoios importantes e com a conquista do público desejado para a Escola de Economia Doméstica, houve dificuldades em sua implantação na cidade de Uberaba, para o que uma série de ações e iniciativas foram necessárias para sua manutenção, o que denota sua importância no projeto de escolarização feminina no âmbito da cidade de Uberaba.

\section{Os saberes disseminados no curso de Economia Doméstica}

A escola tinha por objetivo incentivar a formação feminina para melhorar as atividades do lar, a partir do ensino de técnicas que tornariam as atividades domésticas mais facilitadas. Em sua grade curricular constavam disciplinas de trabalhos práticos, como corte e costura, cuidados com a higiene, culinária, enfermagem, puericultura, além da aprendizagem dos princípios da atividade agrícola. No quadro apresentado a seguir é possível visualizar as finalidades de algumas disciplinas ofertadas no curso. 
Quadro 1 - Finalidades de algumas disciplinas do Curso de Economia Doméstica (1953-1963).

\begin{tabular}{|c|l|}
\hline Arte Culinária & $\begin{array}{l}\text { Habilitar a estudante sobre a importância da nutrição e dos alimentos para a família, } \\
\text { a comunidade e o país; planejar racionalmente a alimentação individual e coletiva } \\
\text { e participar de programas afins. }\end{array}$ \\
\hline $\begin{array}{c}\text { Vestuário } \\
\text { (Corte e } \\
\text { Costura) }\end{array}$ & $\begin{array}{l}\text { Base para o planejamento, confecção, conservação e higiene de roupas pessoais e } \\
\text { da habitação; envolvia aspectos históricos, psicológicos, sociológicos e } \\
\text { econômicos. Habilitar a estudante para orientar a família na melhor utilização dos } \\
\text { recursos destinados às vestimentas dos membros da família, incluindo as crianças. }\end{array}$ \\
\hline $\begin{array}{c}\text { Higiene e } \\
\text { Puericultura }\end{array}$ & $\begin{array}{l}\text { Proporcionar à estudante os conhecimentos necessários à preservação e melhoramento } \\
\text { de saúde do indivíduo e da comunidade e à conservação do ambiente. }\end{array}$ \\
\hline $\begin{array}{c}\text { Administração } \\
\text { do Lar }\end{array}$ & $\begin{array}{l}\text { Fornecia elementos para tomada de decisões no lar, contendo subsídios para } \\
\text { capacitar profissionais a orientar as famílias no reconhecimento e uso dos recursos; } \\
\text { orientar e/ou executar programas de informação e educação do consumidor, para } \\
\text { aquisição e uso de serviços e bens de consumo. }\end{array}$ \\
\hline Psicologia & $\begin{array}{l}\text { Focalizava o processo de desenvolvimento humano visando possibilitar melhor } \\
\text { atuação da Economista Doméstica em órgãos públicos, privados e serviços de } \\
\text { extensão rural e urbana. }\end{array}$ \\
\hline
\end{tabular}

Fonte: Elaborado pelas autoras.

A Escola de Economia Doméstica visava formar a mulher moderna, sobretudo, no sentido da aquisição de uma racionalidade técnica, porém, voltada para o matrimônio, pois ela seria a responsável pelo bom andamento do lar. Acrescentava-se, deste modo, uma nova dimensão ao papel da mulher, todavia, sem alterar sobremaneira a ordem vigente. Nessa direção, é interessante ler um texto de época no qual se demonstrava uma representação muito disseminada no meio social acerca das atitudes das mulheres esperadas pelos homens no âmbito familiar e social. Texto este que foi escrito por Mercês Maria Moreira, com publicação em 29 de agosto de 1953, no Correio Católico, a saber:

As moças são a imagem preciosa de nossa mãe quando tinha nossa idade. [...] um famoso semanário francês dedicado à mulher realizou uma espécie de investigação elegante, entre homens ilustres, a fim de apurar quais motivos prendem um homem ao lar [...] 1. O sorriso da esposa. 2. A mesa bem-posta e os pratos gostosos. 3. O conforto que os faz sentir em sua própria casa. 4. O acolhimento que a esposa faz a seus amigos, levando-os a fazer boa figura. 5. Os móveis de bom gosto completados por um arranjo de bom gosto. 6. A ordem e certa vaidade feminina. 7. O respeito e a compreensão que a esposa nutre pelo seu trabalho. 8. Os filhos bem-educados. 9. O calor do afeto familiar (Ferreira \& Gonçalves Neto, 2013, p. 259-260)

Conjugar a imagem da mulher ideal, conforme exposto no texto acima, com a necessidade dela ter acesso à instrução, neste caso, direcionada à aquisição de conhecimentos científicos sobre as atividades domésticas, não era uma tarefa fácil, mas, a estratégia de evidenciar que, mediante está formação, a mulher estaria mais bem preparada para as atividades que assumiria no lar, bem como para subsistir em caso de alguma dificuldade, parece ter encontrado alguma êxito, conforme era apregoado por Mendonça (1954, p.1), a saber:

O ensino de economia doméstica tem por finalidade preparar moças e senhoras da vida rural para as atividades da vida prática, visando principalmente orientá-las e fornecer-lhes noções técnicas sobre organização, controle e direção do lar, a fim de que se tornem aptas para 
dar ao ambiente familiar as devidas condições de conforto, higiene e harmonia, capazes de promover o aconchego e o bem estar de todos os membros da família, tornando-lhes a vida mais agradável e mais digna de ser vivida. Assim, a orientadora do Centro de Treinamento de Economia Doméstica deve dedicar-se tanto à aprendizagem técnica quanto à formação moral das alunas, fazendo-as compreender a sua imensa responsabilidade como colaboradora do homem e mantenedora do equilíbrio e felicidade da vida doméstica. Ao lado do objetivo principal, que já foi a formação de boas donas de casa, o Centro de Treinamento de Economia Doméstica, através das diferentes aprendizagens técnicas, proporcionará às alunas possibilidades de prover honestamente a sua subsistência, caso necessitem exercer uma atividade lucrativa, desenvolvendo-lhe, ao mesmo tempo, o espírito de cooperação social.

No discurso proferido por Mendonça, percebe-se a preocupação com o preparo das moças para assumirem o papel de administradoras do lar com mais preparo, trazendo ao espaço familiar mais equilíbrio e harmonia. Destaca ainda que seria uma forma das mulheres que fossem menos favorecidas ou que passassem por alguma dificuldade delas terem uma atividade de subsistência por meio da formação recebida por aquele estabelecimento de ensino. Destaca-se ainda, a ideia de cooperação social, em meio a uma sociedade urbana e industrial que se consolidava.

Nesta época, não havia uma matriz unificada para as disciplinas ministradas nas escolas profissionalizantes. Assim, cada instituição escolhia as disciplinas e respectivas cargas horárias com base no Decreto 38.042, de 10 de outubro de 1955 (Brasil, 1955), no qual se regulamentou os currículos do Ensino Agrícola. Esse quadro só passou por modificações com o surgimento da Coordenação Nacional do Ensino Agrícola (Coagri), a partir de 1978, quando foram iniciados estudos para a unificação das atividades desenvolvidas nas Escolas Federais que ofereciam o ensino secundário.

Deste modo, o currículo dependia de aprovação da Superintendência do Ensino Agrícola e Veterinário (Seav), órgão vinculado ao Ministério da Agricultura. Para tal, eram realizados encontros anuais de Diretores dos Colégios Agrícolas e de Economia Doméstica. Isso significa dizer, que o currículo adotado nas instituições precisava do crivo de técnicos e especialistas desse órgão, que faziam os ajustes às reais necessidades do ensino no nível secundário.

Oficialmente, o currículo estabelecido devia obedecer às prescrições recebidas desse órgão que, por sua vez, enviava às escolas as instruções necessárias. Esse trabalho era feito pela Divisão de Estudos Pedagógicos da SEAV, que geria o currículo e as disciplinas a ser ministradas nas escolas. Ao final do curso, as alunas aprovadas recebiam o diploma de licenciada em Economia Rural Doméstica. Para Ferreira (2014, p. 354),

A diversidade e a dimensão das aprendizagens destinadas às moças eram abrangentes. As disciplinas com a inclusão de aulas teóricas e práticas tornavam-se referência para um novo ritmo de ensino, para demarcar a escolarização ofertada e legitimar o trabalho da Eserd na comunidade, fundada em princípios de uma racionalidade para o mundo da produção instituída pelos governantes ao qual a instituição estava subordinada. Isso estabelecia uma estreita relação entre gestores e comunidade considerando as ações mais práticas e presentes no cotidiano. 
Nesse sentido, as aulas não estavam atreladas apenas as questões teóricas, mas havia também uma diversidade de atividades práticas, importantes para a formação das alunas na escola, a saber:

Os departamentos de ensino destinados à Economia Doméstica da Eserd contavam com laboratórios, aparelhos, utensílios de cozinha, lavanderias, sala de corte e costura. Nesses departamentos eram desenvolvidas muitas atividades práticas por meio das quais as estudantes realizavam várias ações que depois poderiam realizar em casa. Ao mesmo tempo, aprendiam a organizar listas de compras, a realizar outros serviços que se ligavam à administração (Ferreira, 2014, p. 357).

Também é importante ressaltar que o curso de Magistério de Economia Rural Doméstica tinha duração de dois anos. Nos quadros que serão apresentados a seguir, é possível vislumbrar as disciplinas do curso, com suas respectivas cargas horárias.

Quadro 2 - Curso Magistério de Economia Rural Doméstica (1954-1955).

\begin{tabular}{|c|c|c|c|}
\hline \multirow{2}{*}{$\begin{array}{c}\text { Disciplinas } \\
\text { Cultura Geral }\end{array}$} & \multicolumn{2}{|c|}{ Aulas semanais } & \multirow[t]{2}{*}{ Total anua } \\
\hline & $\mathbf{1}^{\mathrm{a}}$ Série & $2^{a}$. Série & \\
\hline Português & 01 & 02 & 90 \\
\hline Matemática & 01 & 02 & 90 \\
\hline Ciências Naturais & 01 & - & 30 \\
\hline Cultura Técnica & $1^{a}$ Série & $2^{a}$ Série & \\
\hline Desenho & 01 & - & 30 \\
\hline Trabalhos Manuais & 01 & - & 30 \\
\hline Corte Costura & 01 & - & 30 \\
\hline Economia Doméstica & 01 & - & 30 \\
\hline Atividades Agrícolas & 01 & - & 30 \\
\hline Industrias Rurais & $1^{a}$ Série & $2^{\mathrm{a}}$. Série & \\
\hline Industrias Rurais Caseiras & 01 & - & 30 \\
\hline Arte Culinária & 01 & - & 30 \\
\hline Prática Ocupacional & & $2^{a}$. Série & \\
\hline Cântico Orfeônico & 01 & 02 & 90 \\
\hline Higiene & & $2^{a}$. Série & \\
\hline Higiene e Dietética & - & 02 & 60 \\
\hline Enfermagem e Puericultura & - & 02 & 60 \\
\hline Metodologia & & $2^{a}$. Série & \\
\hline Metodologia & - & 02 & 60 \\
\hline Psicologia & - & 02 & 60 \\
\hline Economia e Administração Doméstica & - & 02 & 60 \\
\hline Total & 11 & 16 & 810 \\
\hline
\end{tabular}

Fonte: Ferreira (2012, p.189-190). 
Quadro 3 - Curso Magistério de Economia Rural Doméstica (1956-1957).

\begin{tabular}{|c|c|c|c|}
\hline \multirow{2}{*}{$\begin{array}{c}\text { Disciplinas } \\
\text { Cultura Geral }\end{array}$} & \multicolumn{2}{|c|}{ Aulas Semanais } & \multirow{2}{*}{ Total Anual } \\
\cline { 2 - 3 } & $\mathbf{1}^{\mathbf{a}}$ Série & $\mathbf{2}^{\mathbf{a}}$ Série & \\
\hline Português & 02 & 02 & 120 \\
\hline Matemática & 02 & 02 & 120 \\
\hline Ciências Naturais & 02 & - & 60 \\
\hline Cultura Técnica & $\mathbf{1}^{\mathbf{a}}$ Série & $\mathbf{2}^{\mathbf{a}}$ Série & \\
\hline Arte Culinária & 02 & - & 60 \\
\hline Economia Doméstica & 02 & - & 60 \\
\hline Corte e Costura & 02 & - & 60 \\
\hline Trabalhos Manuais & 02 & - & 60 \\
\hline Atividades Agrícolas & 02 & - & 60 \\
\hline Desenho & 02 & - & 60 \\
\hline Psicologia & - & 02 & 60 \\
\hline Higiene & - & 02 & 60 \\
\hline Metodologia Especial & - & 02 & 60 \\
\hline Enfermagem e Puericultura & - & 02 & 60 \\
\hline Administração Escolar & - & 02 & 60 \\
\hline Agricultura & - & 02 & 60 \\
\hline Arte Culinária e Indústrias Rurais & - & 02 & 60 \\
\hline Práticas Educativas & $\mathbf{1}^{\mathbf{a}}$ Série & $\mathbf{2}^{\mathbf{a}}$. Série & \\
\hline Jogos Educativos & - & 01 & $\mathbf{1 3 5 0}$ \\
\hline Canto Orfeônico & 01 & 02 & \\
\hline Total & $\mathbf{2 0}$ & $\mathbf{2 5}$ & \\
\hline
\end{tabular}

Fonte: Ferreira (2012, p. 190).

Documentos encontrados no acervo da instituição indicam que além da inscrição, era necessário fazer um exame de admissão. De acordo com Ferreira (2014, p. 360), no decorrer do ano letivo, as provas eram mensais com os devidos registros em atas. As provas de $2^{\mathrm{a}}$ época - período de recuperação para quem não obteve conceitos satisfatórios - eram aplicadas, caso as estudantes não alcançassem média em uma das disciplinas. E se fossem reprovadas, ainda podiam se matricular na série seguinte e cumprir a disciplina em outras turmas e horário.

A partir de 1963, ano em que a escola foi transformada em escola técnica, os cursos passaram a abranger o Ginasial Agrícola e o Colegial de Economia Doméstica Rural para atender às prerrogativas previstas na LDBEN de 1961. Os Cursos Ginasiais de Economia Doméstica Rural tinham, em sua essência, a mesma finalidade de antes, procurar desenvolver nas estudantes as aptidões para as lides domésticas, preparando-as para as responsabilidades e atividades do lar e para as atividades sociais.

O desenho do perfil formativo das alunas era assentado em práticas escolares e culturais que denotavam valores morais católicos, tidos, inicialmente, como parâmetro de referência para a atuação docente, mas, por desdobramento, também para as alunas. Assim, a forma de se comportarem e de se vestirem refletia os valores nacionais e locais hegemônicos na época, conforme é evidenciado no depoimento apresentado em Ferreira (2014, p. 346): 
Nosso uniforme era como o do uniforme do Uberaba Esporte: saia vermelha godê e blusinha branca. Foi o primeiro uniforme. O Padre Vicente foi nosso professor de Educação Artística. Ele montou o Coral. Cantávamos na Praça do Mercado. As professoras deveriam usar saia com o comprimento abaixo do joelho vinte centímetros. Não podiam usar calça comprida, nem blusa sem manga. Era a lei do governo. Usávamos jaleco, mas deixávamos na escola. Uma professora quando veio de Viçosa para me substituir, vindo da universidade, com o jeito de gente jovem, saia mais curta. A Diretora me chamou e disse-me para conversar com ela como deveria se vestir. [...] Depois da nossa conversa, ela se vestiu de freira. Tive de dizer a ela "nem tanto, de jeito nenhum".

Este contexto moral vivido nos primeiros anos de funcionamento da escola é evidenciado na figura apresentada a seguir, na qual a presença de um padre na regência do Coral denota que a Escola se consolidava na sociedade uberabense como sendo uma instituição de "boas e sadias relações sociais, local de ética e de virtude, na qual os pais confiariam matricular suas filhas" (Ferreira, 2014, p.347).

Figura 4 - Apresentação do Coral da escola (1955).

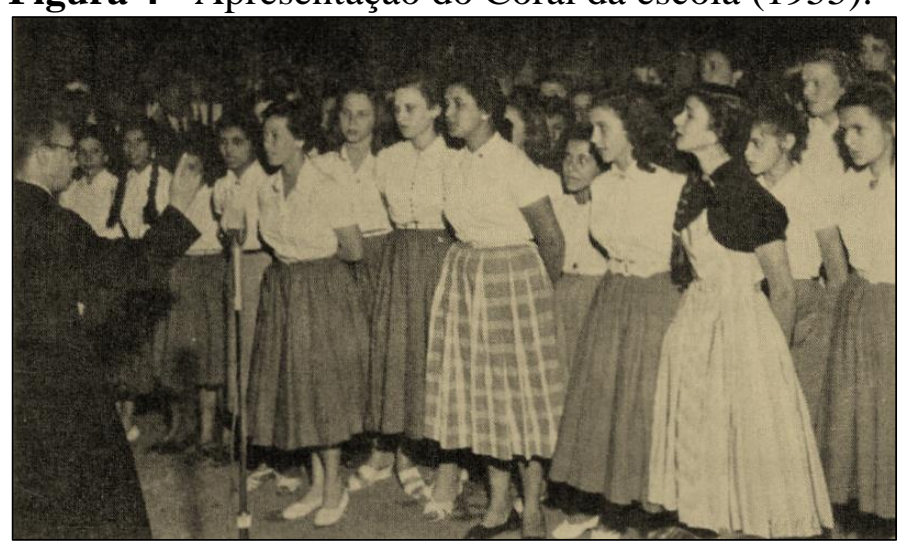

Fonte: Acervo do IFTM.

É possível também analisar por meio da imagem as alunas da escola estavam bem vestidas, o que permite afirmar que elas, de modo geral, tinham boa condição financeira, o que também é mencionado em outro depoimento apresentado em Ferreira (2014, p. 349):

As alunas de Economia Doméstica eram todas de famílias bem situadas na vida, com poder aquisitivo. Muitas são minhas amigas até hoje. Tínhamos muita amizade. Era muito bom, muito divertido. As alunas de Economia Doméstica eram chamadas de "espera-marido". Quando pegavam ônibus, outros alunos de outros cursos as chamavam assim. Elas retrucavam e chamavam os alunos que estavam no mesmo ônibus de pedreiros.

As atividades festivas, tais como os eventos cívicos e as festas sociais, tinham a participação das alunas da escola. Abaixo pode-se visualizar a imagem da oradora da primeira turma de formandas do curso de Economia Doméstica. Percebe-se o cuidado com o vestir, bem como com a postura, elementos muito valorizados e considerados importantes para a sociedade da época e disseminados pela escola. 
Figura 5 - Oradora da $1^{\text {a }}$ turma de Economia Doméstica em 1955.

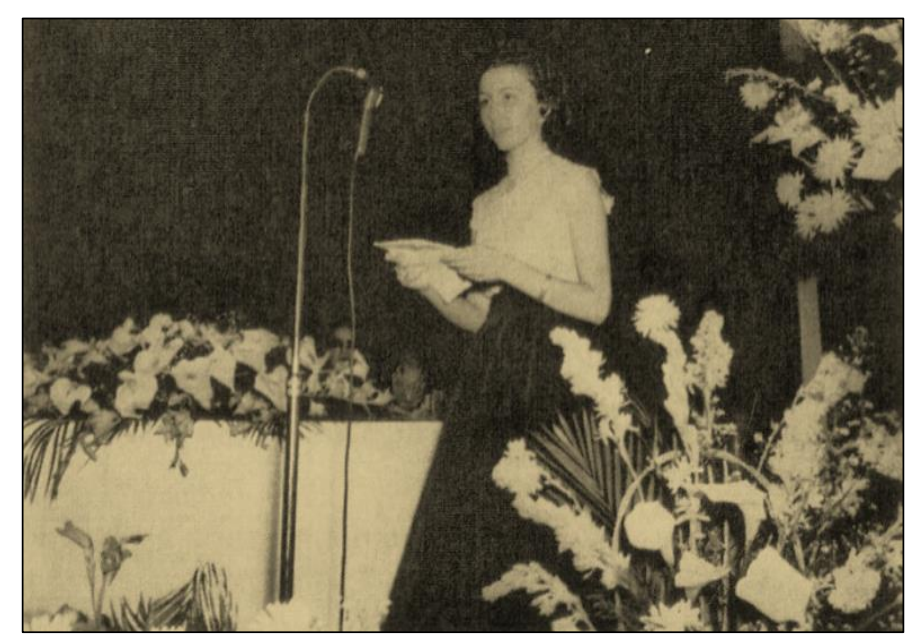

Fonte: Acervo IFTM.

Na análise de Ferreira (2014, p.312), a visão que se tem é a de que a atitude denotava o senso de responsabilidade apregoado pela escola, "a noção de deveres a serem cumpridos para com a comunidade da qual se era membro, incluindo posturas adequadas, coerente com os ideais republicamos de se desempenhar fielmente as obrigações contraídas com a formação educacional". Coadunavam-se na formação os saberes disciplinares, relacionados a aquisições científicas, com a disseminação de valores morais, simultaneamente, de corte cívico-patriótico e católico.

\section{Considerações finais}

Ao abordar a criação e os primeiros tempos da Escola de Economia Doméstica na cidade de Uberaba (Minas Gerais, Brasil) percebe-se a importância que essa instituição teve no processo de escolarização feminina nesta cidade na região circundante. Alinhada a conjuntura de uma época, na qual a moral e os bons costumes estavam em pauta e o processo de modernização da cidade impunha-se, houve esforços na direção da formação mais elaborada para as mulheres, conjugando civismo e preceitos católicos.

Percebeu-se que o empenho pessoal do Padre Agostinho Zago, apoiado pela Igreja, pela elite política e pela sociedade civil, contribuiu para que esse estabelecimento de ensino fosse criado em Uberaba, bem como, para que a escola tivesse uma primeira turma de alunas.

Mediante o alinhamento de preceitos morais católicos e de pressupostos cientificistas e higienistas, as mulheres tornaram-se fundamentais para o aperfeiçoamento da saúde familiar e na melhoria das condições de vida no âmbito familiar e comunitário. De acordo com Rato (1992, p.40), a difusão das ideias de modernização das famílias exigia a criação de um curso que "ensinasse" os comportamentos morais e materiais condizentes com a nova ordem social.

Nessa perspectiva, a criação da Escola de Economia Doméstica atendia a esses preceitos, por meio de um currículo que preconizava os cuidados com o lar e com a família. As disciplinas ministradas denotam essa ideia de cuidado com o lar, com a família.

Muito embora, em um primeiro momento, a ideia fosse preparar a mulher para os cuidados diários com a família, o curso tornou-se mais tarde uma porta de entrada para a atuação profissional feminina. $\mathrm{O}$ fato é que, seja no lar, seja no mundo do trabalho, a mulher deveria representar um modelo de conduta ilibada e responsável pelo alicerce familiar, por meio do qual ela imprimiria na sociedade as virtudes femininas necessárias ao contexto social. 


\section{Referências}

AMORIM, N.B. Entrevista. Jornal da Manhã Online. 12 fev. 2012. Disponível em http://www.jmonline.com.br/novo/?colunas,27,ENTREVISTA,13/02/2012. Acesso em 10 jun. 2018.

BRASIL. Ministério da Agricultura. Decreto n. 38.042 de 10 out. 1955. Aprova o Regulamento dos Currículos do Ensino Agrícola. Disponível em http://www2.camara.leg.br/legin/fed/decret/1950-1959/decreto-38042-10-outubro-1955-335142publicacaooriginal-1-pe.html. Acesso em 10 jun. 2018.

CORREIO CATÓLICO. O correio no lar - moças. Uberaba. 29 ago. 1953, p. 5.

FERREIRA, N.V.C. Economia Doméstica: ensino profissionalizante feminino (Uberaba/MG, 1953-1997). Jundiaí/SP: Paco Editorial, 2014.

FERREIRA, N.V.C. Escola de Economia Rural e Doméstica: ensino secundário profissionalizante no Triângulo Mineiro (1953-1997). Tese. 294f. Doutorado em Educação. Universidade Federal de Uberlândia. 2012.

FERREIRA, N.V.C. \& GONÇALVES NETO, W. Organização inicial do ensino profissionalizante feminino em Uberaba/MG: economia rural doméstica (1953-1962). Revista HISTEDBR On-line. n.51, p.252-265, jun. 2013.

MENDONÇA, J. Discurso pronunciado em 03/05/1954, na inauguração da Escola de Economia Doméstica, em Uberaba (MG). Disponível em http://josemendonca.com.br/ discurso_ED_03051954.php. Acesso em 10 jun. 2018.

RATTO, I.M.R. A visão de família nos cursos de Economia Doméstica. Dissertação. Mestrado em Ciências Sociais em Desenvolvimento, Agricultura e Sociedade. Universidade Federal Rural do Rio de Janeiro. 1992. 